\title{
ANNOTATED BIBLIOGRAPHY ON HIGHWAY TRAVEL EXPOSURE RESEARCH METHODS
}

\author{
Arthur C. Wolfe \\ Highway Safety Research Institute \\ The University of Michigan \\ Ann Arbor, Michigan 48109
}

Contract No. DOT HS-7-01685

Contract Amt. $\$ 62,500$

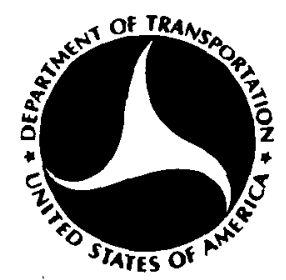

JANUARY 1978

INTERIM REPORT

This document is available to the public through the National Technical Information Service, Springfield, Virginia 22161

Prepared For

U.S. DEPARTMENT OF TRANSPORTATION
National Highway Traffic Safety Administration
Washington, D.C. 20590


This document is disseminated under the sponsorship of the Department of Transportation in the interest of Information exchange. The United states Government assumes no liability for 1ts contents or use thereof. 


\begin{tabular}{|c|c|}
\hline $\begin{array}{l}\text { 1. Roport No. } \\
\text { DOT HS-803 } 295\end{array}$ & 3. Recipient' Coralog No. \\
\hline \multirow{3}{*}{$\begin{array}{l}\text { Annotated Bibliography on Highway Travel } \\
\text { Exposure Research Methods }\end{array}$} & 5. Roport Dore \\
\hline & January 1978 \\
\hline & 8. Performing Orgonizelion Report No. \\
\hline $\begin{array}{l}\text { 7. Author's) } \\
\text { Arthur C. Wolfe }\end{array}$ & UM-HSRI-78-7 \\
\hline 7. Performing Organi zotion Name and Address: & 10. Work Unit No. (TRAIS) \\
\hline \multirow{2}{*}{$\begin{array}{l}\text { Highway Safety Research Institute } \\
\text { The University of Michigan } \\
\text { Ann Arbor, Michigan } 48109\end{array}$} & 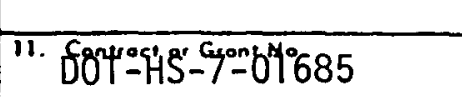 \\
\hline & 13. Type of Report and Period Covered \\
\hline \multirow{2}{*}{$\begin{array}{l}\text { 12. Soonsoring Agoncr Name and Adres: } \\
\text { U.S. Department of Transportation } \\
\text { National Highway Traffic Safety Admin. }\end{array}$} & $\begin{array}{r}\text { Interim Report } \\
8 / 1 / 77-1 / 31 / 78\end{array}$ \\
\hline & 14. Sponsoring Agency Code \\
\hline
\end{tabular}

15. Supplementory Notes

16. Abstroct

This report contains 87 entries relating to issues, methods, and results of research concerned with the measurement of highwäy travel exposure to the risk of accident, many focusing specifically on the measurement of vehicle miles traveled as the denominator. in the calculation of accident rates for different categories of diver, vehicle, and environmental characteristics. Included are studies which make use of existing public record data; studies which obtain data by roadside counting, roadside observation, and roadside interview; and studies which obtain data by home and licensing office interviews and questionnaires (using in-person, telephone, and mail techniques).

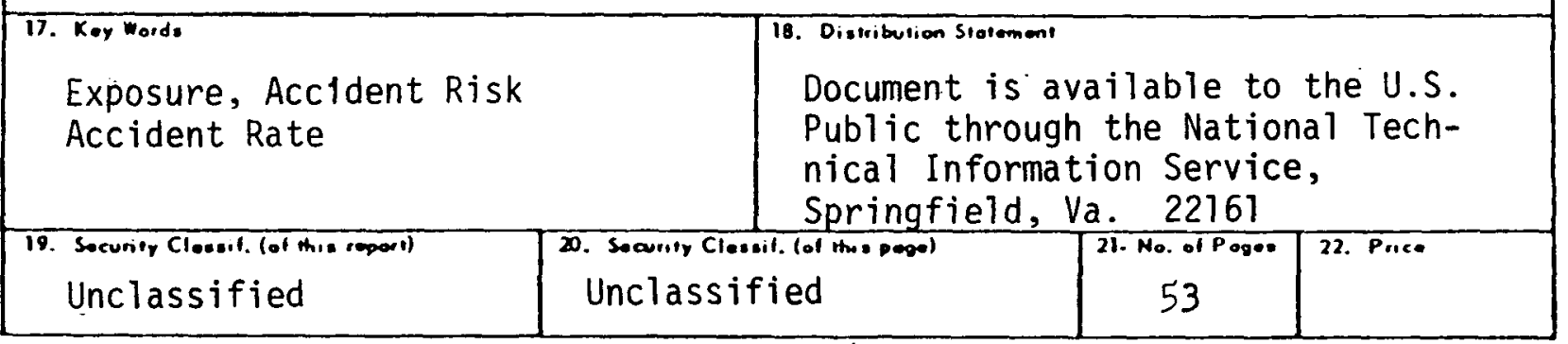

Form DOT F $1700.7(8-72)$

Reproduction of complated poge authorized 


\section{METRIC CONVERSION FACTORS}

Approximate Conversions to Metric Measures

Symbol

When Yeu Know

Multiply by

To Find

$\stackrel{\sim}{\sim}$

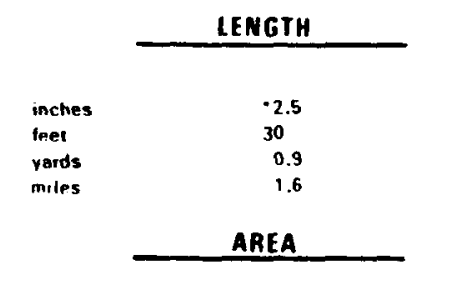

square teet

square vards

6.5

$\mathrm{nn}^{2}$
$\mathrm{n}^{2}$
$\mathrm{rd}^{2}$
$\mathrm{mi}^{2}$

acres

MaSS (weight)

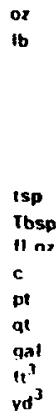

tsp
Tbsp
"n?
pt
at
gat
"i?
vd $^{3}$

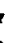

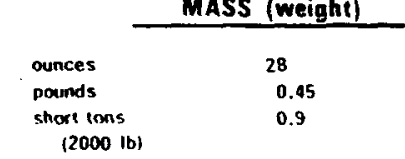

VOLUME

\begin{tabular}{|c|c|}
\hline teaspoons & 5 \\
\hline cablespoons & 15 \\
\hline 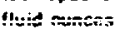 & so \\
\hline cusps & 0.24 \\
\hline pints & 0.47 \\
\hline Guarts & 0.95 \\
\hline galloms & 3.8 \\
\hline cubuc: teet & 0.03 \\
\hline
\end{tabular}

TEMPERATURE (exact)

$\begin{array}{ll}\text { Fahrenheit } & 59 \text { latter } \\ \text { temperature } & \text { subrracting }\end{array}$

32)

moterss

hectures

grams

kilograms
immies

Celsums

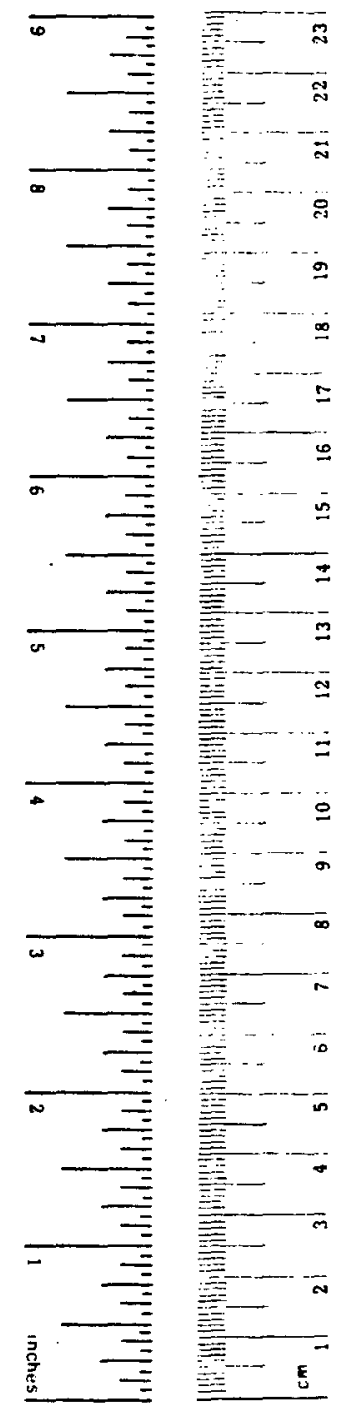

Approximate Conversions from Matric Measures

Symbal

Multiply by

To Find

Srmitol

LENGTH

$\begin{array}{lll}\text { millimeters } & 0.04 & \text { inches } \\ \text { centimeters } & 0.4 & \text { inches } \\ \text { meters } & 3.3 & \text { feet } \\ \text { meters } & 1.1 & \text { vards } \\ \text { kilompters } & 0.6 & \text { miles } \\ & & \end{array}$

$\stackrel{c m}{m}$

centumeters
centumetrors

square centumeters

square mpters

syuare kilometers

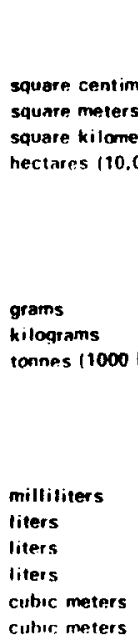

AREA

$\begin{array}{lll}\mathrm{cm}^{2} & \text { square centimeters } & 0.16 \\ \mathrm{~m}^{2} & \text { square meters } & 1.2\end{array}$

square meters

1.2
0.4 square vards square miles

ham

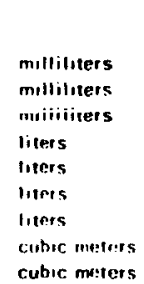

cubic meterers

MASS (weight)

grams
kilograms
tonnes

0.03

1

ounces

Dounds
short tons

or

VOLUME

millifiters
liters
liters
liters
cubic meters
cubir: meters

0.03
2.1
1.06

2.1
1.06
0.26
35

Huid ounces

oints

gallons

cubic reet

110
$a$
$a t$
$9 a 1$
$" 1$
$d^{3}$

\section{TEMPERATURE (exaet)}

$\frac{\begin{array}{c}\text { Celsius } \\ \text { temperature }\end{array}}{\begin{array}{c}9 / 5 \text { lithen } \\ \text { add } 321\end{array}}$

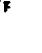


The Highway Safety Research Institute of the University of Michigan has a contract from the National Highway Traffic Safety Administration to design a National Exposure Data System to complement the National Accident Sampling System currently being implemented by NHTSA. A major goal of both of these data collection systems is to determine reliable national accident rates for various classes of vehicles, drivers, roads, environmental conditions etc.

The first stage of this project involved an extensive background review of studies which have used various methods of collecting exposure data. The following report annotates a wide variety of methods which have been used to collect exposure information on motor vehicle travel in the United States and in other countries. It is published in the hope that bringing this methodological information together in one document will be useful to many members of the transportation research community. 


\section{TABLE OF CONTENTS}

A. General Concepts of Exposure Measurement ' 1

B. Use of Existing Public Records 5

C. Use of Traffic Count Data 9

D. Use of On-Road Observations 15

E. Use of On-Road Observations with Follow-ups 19

F. Use of Roadside Interviews 21

G. Use of Home In-Person Interviews 25

H. Use of License Renewal Office Interviews or Questionnaires

I. Use of Telephone Interviews $\quad 35$

J. Use of Mail Questionnaires 37

K. Comparisons of Various Exposure Data Collection Methods 41

L. Comparisons of Various Exposure Measurement Methods 45 
A. GENERAL CONCEPTS

A1. Battey, Alvan D. "The Measurement of Exposure to Motor Vehicle Accidents," Traffic Engineering 29(6):21-24 (March 1959).

Suggests using different bases for studying yearly trends in three different types of fatal accidents: 1) for collisions with pedestrians multiply the annual VMT by an index of population increase from a base year; 2) for collisions of 2 or more motor vehicles use the square of the annual VMT; and 3) for other accidents use the annual VMT. Also suggests picking a base year and measuring trends for each accident type by an index number; the three indices would be combined by multiplying each index by its \% of fatal accidents in the base year, summing the results, and dividing by 100; as an example, if 1947 was chosen as the base year with an overall index of 100,1957 would have an overall index of 56. Suggests the desirability of constructing such trend indices separately for urban and rural areas; also for injury accidents and property accidents if reporting were more complete.

Mentions that in the 1953-1958 period the average miles travelled per vehicle varied 1 ess than $1 \%$ from one year to the next (range was between 9608 and 9674 ) and that in the 1946-1958 the yearly variation was never greater than $2 \%$.

A2. Carroll, Philip S. "The Meaning of Driving Exposure." HIT LAB Reports (Apri1 1971), pp. 1-3.

Proposes defining driving exposure as "the frequency of traffic events which create a risk of accident"; suggests that in this definition exposure may be measured directly by units of driving distance or driving time classified by variables which contain different categories of relative risk--variables relating to the driver, the vehicle, the roadway, and the environment (including such risk variables as speed and density).

A3. Carro11, Philip S. Symposium on Driving Exposure, Ann Arbor: Highway Safety Research Institute, 1973.

A summary report on discussions at a 3-day seminar on driving exposure held in Washington in June 1973 with 25 participants; the symposium discussed many conceptual and methodological issues in driving exposure research and recommended a phased development of a national exposure data collection system based on measuring vehicle miles travelled cross-classified by age and sex of driver, vehicle type, vehicle make and year, road type, and day/night.

A4. Chapman, Roger A. "The Concept of Exposure," Accident Analysis and Prevention 5(2): 95-110 (June 1973). 
A brief review of the concept of exposure and of many studies of accident rates with particular emphasis on intersection accidents; defines exposure as a measure of the opportunities/or possibilities of having an accident but does not recommend any particular means of measurement; includes an extensive Bibliography of relevant exposure literature used in the author's P..D. thesis at University College, London (Some Relationships Between Road Accident Frequencies and Measures of Exposure to Risk, 1971).

A5. Eicher, John P. "The Fallacy of the Accident Rate Concept", Bureau of Public Roads unpublished paper, 1968.

Reviews previous discussion and provides new data on the fallaciousness of the assumption of linearity in basing accident rates on vehicle miles traveled; used 1963 and 1964 data from 37 states on accidents on interstate and other main roads controlling on urbanicitiy, lanes and access control to demonstrate that numbers of accidents do not increase linearly with either average: daily traffic volume or with segment length (at least 5 segments in each of 45 classes used) - based on regression analysis. However, due to inconsistent results on different road types no alternative assumptions were found satisfactory, and continued cautious use of VMT was recommended as a base for accident rates - recognizing that for engineering purposes comparisons of rates for similar length and traffic volume segments are most meaningful.

A6. Mela, Donald F. "Exposure Data Needs" in Motor Vehicle Collision Investigation Symposium Volume I: Proceedings, edited by John W. Garrett, Washington: Contract No. DOT-HS-5-01135, 1976, pp. 132-142.

Discusses the practical impossibility of actually observing and measuring in degrees all the potential hazards to which a driver is exposed on the road and the need in accident analyses to obtain at least indirect measures of exposure such as vehicle miles of travel, hours of driving, etc. cross-classified on as many relevant variables as feasible.

A7. Rabe, F.T. and M.A. Cassella "Modeling Vehicle Milles of Travel: The State of the Art", in Automotive Energy Efficiency Program: Papers Presented at the Project Coordination Meeting Nov. 4-6, 1975. Cambridge Mass. DOT Transportation Systems Center, June 1976, PP. 197-209.

Previous models for projecting future national VMT are inadequate because they are too simplistic or too localized (urban travel demand surveys); a more adequate model can be specified but is difficult to implement because of the lack of an up-to-date nationally representative sample of needed household data on individual travel decisions in relation to auto ownership, residential location, etc. 
A8. Stewart, Roger G. "Driving Exposure: What Does It Mean? How Is It Measured?", Iraffic Safety Research Review 4(2):9-11 (June 1960).

Report of a study of 126 male college students seekịng to determine if total annual mileage or mileage classified in various dichotomized categories (based on percentage estimates of day-night, city-country, and light-heavy traffic) was related to accident or citation experience; only one of 45 chi squares was significant at the .05 level; concludes that mileage may not be a very satisfactory indicator of an individual driver's exposure to accident.

A9. Waller, Julian A. "Issues Concerning Measurement of the Population at Risk in Crashes", Paper Presented at Second National Forum on Traffic Records Systems, St. Louis, 1976.

Suggests that good accident exposure information subclassified as much as possible is needed for the measurement of relative frequencies, causal factors, and countermeasure effectiveness; illustrates these needs by discussion of nine statements about different aspects of highway safety which can't be demonstrated without appropriate and accurate exposure data; discusses problems with mileage estimates from gas sales or household surveys (annual mileage estimates tend to be by thousands and five thousands or $12,000,24,000$, etc.) household survey reports for specific 24 hour periods may be somewhat better).

Suggests the roadside survey as the potentially most effective method but very costly if involves stopping drivers; suggests selection of representative sites on roads which are not likely to change over time (obviously hasn't thought out problems of a true probability site selection process); says that a roadside survey cannot provide absolute VMT information (not correct if used with traffic counting) but that the relative exposure information it could provide would be very valuable.

A10. Waller, Patricia F., Donald W. Reinfurt, Jean L. Freeman, and Peter B. Imrey. "Methods for Measuring Exposure to Automobile Accidents", Paper Presented at the 101st Annual Meeting of the American Public Health Association, San Francisco, 1973.

Report of a 1971 study in North Carolina which attempted to validate J.D. Thorpe's "induced exposure" method, which assumes that the characteristics of accident-causing drivervehicle combinations in multi-vehicle accidents are similar to those of single vehicle accident driver-vehicle combinations, and that the "innocent" driver vehicle combinations in multivehicle accidents provide a good representation of the population at risk. This study compared the age and sex percentages 
for in-state single-vehicle accidents and for in-ștate multi-vehicle accidents in which one driver was considered in violation with sex and age exposure percentages from a survey of daily or weekly mileage from applicants aged 20 or more in N.C. license renewal offices. "Innocent double" drivers were found to more closely resemble the license renewal applicant's exposure distribution than the "guilty double" drivers, espectally the females in 7 age groups, but not close enough to really validate the method. However, single vehicle accident drivers were substantially different from "guilty double" accident drivers (former much younger), thus invalidating Haight's suggestion (1970) of using single-vehicle accident drivers as a surrogate for "guilty double" accident drivers. A comparison of license renewal applicants' exposure distributions with that of a weekday 0 \& D survey in the Goldsboro area showed fairly similar distributions. Discusses the problem of using mileage as an exposure measure (defined as "probability of encounter") because mileage does not take duration into account; one can't assume equality in speed or other road conditions for different groups of drivers. Concludes that there are good reasons why the induced exposure method should not agree with the mileage method but that it is impractical to validate it against any other objective criteria and therefore it is not an appropriate scientific measure of exposure. 


\section{B. USE OF EXISTING PUBBLIC RECORDS}

B1. Dutt, Amitabh K. and Donald W. Reinfurt... Accident Involvement and Crash Injury Rates by Make, Model, and Year. of Car: Final

Report and Accident Involvement and Crash Injury Rates by Make, Model, and Year of Car: A Follow-up, Chapel Hill, N.C.: Highway Safety Research Center, June 1977.

Two similar reports using North Carolina accident, registration and inspection data for 1974 and 1975 respectively to estimate accident rates for various passenger car categories. The VMT denominator in these rates was determined by using a large sample of vehicle inspection receipts which contained the current and previous odometer reading, the current and previous inspection date, and the vehicle license number. The actual or interpolated annual mileage was obtained for as many of these vehicles as possible, and then the license number was used with the registration file to obtain the vehicle VIN number and thus information on its make, model, and year. Mileage and vehicle classification information was available for only about $30 \%$ of the original sample, but these remaining good cases were used to obtain an average annual VMT for each vehicle class. Then the registration files were analyzed to determine the total number of vehicles in each class, and the two numbers were multiplied to obtain the total annual VMT for each class. Similarly the VIN numbers in the accident files were used to obtain vehicle class information for accident involved vehicles, and the number of vehicles in each class was counted to create the accident numerator. Unfortunately, about one third of the accident-involved vehicles lacked usable VINs, so the presented accident rates are substantially lower than their expected true values, but they can still be used for relative comparisons among different vehicle classes. In addition to the tables of accident rates by various vehicle categories overall and controlling on such variables as accident road type, weather, time of day, and vehicle maneuver, there are some interesting tables comparing average annual VMT for various vehicle classes.

The second study also looked at inspection data on headlight, brakelight, brake, and tire defects in relation to vehicle class and total mileage; there was a closer relationship between defects and car age than between defects and total mil leage per se.

The authors recommend that in a future North Carolina study that fewer of the 6000 inspection stations be sampled over a longer period in order to permit closer monitoring of the 
recording of the needed mileage and license number data on the inspection receipts, and that the vehicle license plate number in the accident records be used in conjunction with the VIN in the registration records to obtain vehicle class information rather than just depending on the frequently unusable VIN in the accident records.

B2, Negri, D. Barry. Vehicle Mìleage Exposure Study: Final Report, Report DOT-HS-800 961 from Contract DOT HS-245-2-476, Sept. 1973,

Report of a study of average annual VMT using over $1,000,000$ New York state vehicle inspection receipts containing pairs of odometer readings. Average annual VMTs are presented by vehicle make/7ine/year; age ( 6 groups) and sex of owner by vehicle make/line/year; age and sex of owner; vehicle model year; vehicle type ( 8 groups); vehicle make/line; and body type for Chevrolets only.

B3. Research Triangle Institute Environmental Analys is Department. Improved Exposure Measurements: Interim Report, Research Triangle Park, N.C., December 1972.

Includes a study of odometer reading data from South Dakota and Washington, D.C., vehicle inspections transformed into annual mileages by the New York State Department of Motor Vehicles; a printout of over 850 pages of vehicle frequency counts by over 3000 make-model and year-weight categories was produced and two sample pages were printed in the report.

B4. Research Triangle Institute Statistical Methodology Department, Improved Exposure Measurements: Phase I Report, Research Triangle Park, N.C., October 1973.

Reviews information relevant to exposure in available state records; found that only two states obtain odometer readings in their vehicle registration files and les:s than half the states obtain odometer readings in conjunction with periodic motor vehicle inspection programs; all states have age and sex of licensed drivers, age and sex of accident drivers, and age and sex of vehicle owners, but not all states have the ability to relate these different files; also all states have programs of traffic counting and origin-destination surveys, but these data are usually limited to certain areas or classes of roads; concludes that existing state data are far from adequate for providing meaningful national measurements of exposure, and summarizes a number of potentfal measures and methods of obtaining better exposure data in the future. 
B5. Research Trịangle Institute. Improved Exposure Measurements: Final Report, Research Triangle Park, N.C., January 1976.

As a precursor to the study by Dutt and Reinfurt reported ahove $(B 1)$, a demonstration of the combined use of vehicle inspection odometer readings and vehicle registration data was carried out in North Carolịna; over 9000 inspection receipts from October 1974 were used to obtain average annual mileages for 18 vehicle classes, the vehicle registration files were analyzed on three different dates to determine the average number of N.C, vehicles in each of these classes during the previous year, and the results were multiplied to provide total annual VMT by vehicle class. In addition a mail survey of a sample of the owners of the inspected vehicles was used to determine the percentage of driving outside of North Carolina and to apportion the vehicle mileages between day/ night and urban/rural categories by age and sex of driver, thus permitting up to 5-way classifications of exposure data for the calculation of accident rates using similar classes of accident data. 
C. COLLECTION AND USE OF TRAFFIC COUNT DATA

C1. Bodle, Richard R. Sampling Surveys for Estimating Local, Rural, and Urban Vehicle-Miles of Travel, Washington, Federal Hfghway Administration, JuTy 1973, 36 pp. (Highway Planning Technical Report No. 31).

Discusses the problem of accuracy in state VMT estimates by road classes, particularly for local rural and urban roads, and describes and illustrates two sampling approaches for obtaining unbiased estimates of VMT with known error terms.

In the area sampling method a region is divided into sampling areas each containing about 50 miles of roads (oniy 5 miles in urban sampling areas), 104 sampling areas are randomly selected (2 per week), and one-week counts are made at 10 points in each area (every 5 miles in rural areas, every $\frac{1}{2}$ mile in urban areas); it is assumed that each vehicle counted represents 5 or .5 VMT in the rural or urban areas respectively. In the pilot study in Colorado in 1970-72 6-day counts were used and expanded because one day was needed to move the counters; the relative error (standard error divided by the VMT estimate) was a somewhat disappointing $31.1 \%$ in the rural sample but was $8.3 \%$ in the urban sample; similarly a 1969-1970 study of Oregon county roads obtained a $26.9 \%$ relative error.

The link-day sampling method is suggested as another approach in urban areas. It involves counting and classifying all road links (a road segment between intersections or other major abutting driveway--e.g., a factory entrance) by ADT volume groups, stratified sampling of these links randomly and assigning them to a random day of the year for a 24 hour count, and multiplying the actual link length times its traffic count to get its VMT; a 1969 pilot study in Oskosh, Wis., and a 1958 study in 15 Idaho cities each obtained relative errors of $6.9 \%$. Appendices explain the methods and the error formulas.

C2. Foldvary, L.A. "Establishing an Organized System of Road Traffic and Transportation Studies", Proceedings of the 1962 Conference of the Australian Road Research Board Vo1. 1, Part 1, pp. 268-317.

A long discussion of the various desirable components of a comprehensive national system of traffic research for many purposes including accident rates; describes a particular method of establishing a sample of 100 permanent traffic counting stations on New South Wales highways, trunk roads, and main roads, using a two dimensional random sampling design-one stratifying by different classes of road ( 3 road types within metro urban, metro rural, other urban, other rural east, and other rural west) and the other stratifying by 
traffic pattern similarities (using the 14 statistical regions of the country as a surrogate)--and using as a measure of size for determining the number of stations for each road class the square root of the estimated average daily traffic on that whole class times the total mileage in that class (following the method established in the U.K.). Includes tables illustrating the application of the method, and a review of some traffic counting methods in the U.S., U.K., and Middle Europe; suggests that this method is good for obtaining unbiased estimates of VMT spatially over short and long time periods; along with this there should be about every 10 years a more extensive general road traffic survey covering a short period plus classification counts of vehicle types and origin-destination studies at inner and outer cordons and a road users survey (classification surveys may need to be done more frequently at the permanent counting stations).

C3. Guide for Traffic Volume Counting Manua], 3rd. ed., Washington: FHWA Bureau of Public Roads, 1970.

Discusses the use of continuous count stations and seasonal count stations (usualiy 7 days once a month or trimonthiy) to expand short coverage count data (24 hr., $12 \mathrm{hr}$., $8 \mathrm{hr}$., or sometimes $48 \mathrm{hr}$. or longer between noon Monday and noon Friday), ADT estimates for both rural and urban roads; includes some rather vague information on accuracy of such estimates and "smoothing" of adjacent counts on a road; gives little guidance as to how to locate the various types of count stations, does not even mention random or probability sampling; does not discuss conversion of count data to miles travelled except in the glossary which states "Vehicle Miles-Normally obtained by multiplying the ADT by 365 and by multiplying the mileage of raod to which the ADT is applicable.

C4. Research Triangle Institute. Improved Exposure Measurements: Final Report, Research Triangle Park, N.C., January 976.

One demonstration project reported by RTI involved the use of hourly traffic count data from the 59 permanent count stations in North Carolina to estimate the proportion of North Carolina driving during the daytime (defined as 7 AM to 7 PM); the daytime percentages on five classes of roads varied from .735 on interstate highways to .793 on rural secondary roads, and these percentages were used with FHWA total VMT estimates for these five classes to obtain total daytime VMT estimates; overall the daylight proportion of North Carolina VMT was estimated as .766. However, given the small number of count stations in each class and the lack of controlled probability procedures in selecting the station locations there is no way to judge the degree of accuracy of these estimates. 
C5. Tanner, J.C., H.D. Johnson, and J.R. Scott, Sample Survey of the Roads and Traffic of Great Britain, London: HMSO, 1962 (Road Research Technical Paper No, 62).

Description of the sample design by which 1123 roadside points were selected to try to represent all the public road mileage $(189,193$ miles in 1956) in Great Britain, using 80 strata consisting of 10 geographic regions and 4 urban and 4 rural road types; there was a minimum of 5 points per stratum and a maximum of 70 ; the selection method gave a somewhat greater chance of selection to points on higher volume roads; all points used in the permanent 50-point traffic census were included automatically; sample selection required the use of $260010 \mathrm{~km}$. by $10 \mathrm{~km}$. maps gridded in one $\mathrm{Km}$. squares.

These points and adjacent sections and jurisdictions were used for a national survey of road characteristics from 1957 to 1959; to scale the survey results up nationally each point in a stratum was weighted by the result of dividing the total mileage in the road class in the geographic area by the number of points in that stratum.

These points were also used for traffic counts in the spring and fall of 1960; at each point 2, 3, or 4 eight hour manual counts of 11 vehicle classes (including pedal cycles) were made either from 6 AM to 2 PM or from $2 \mathrm{Pm}$ to $10 \mathrm{Pm}$; scaling to 24 -hour counts and to the year from November 1959 to October 1970 was carried out using the data from the permanent 50-point traffic census; vehicle miles were apparently determined by weighting the traffic count at each point by the stratum scaling factor, thus assuming each count equals 1 mile of travel; the estimated coefficient of variation for the whole survey was only $3.1 \%$.

C6. Tanner J.C. and J.R. Scott, 50-Point Traffic Census--The First Five Years, London:HMSO, 1962 (Road Research Technical Paper No. 63).

Description of the sampling procedure by which 50 points on 8 classes of British roads were selected (spread among 10 geographic divisions) in 1956 for the installation of permanent traffic counters; in addition 16-hour manual vehicle type counts were made at these points for 3 days (Friday, Saturday, Sunday) almost every month beginning in 1957; over the first 5 years $14 \%$ of the daily counts were not available due to breakdowns or other causes, and adjustments were made for these missing data in the report on monthly and annual trends; the method of translating the traffic counts into vehicle miles traveled is not explained. 
C7. Timbers, Janice A. Traffic Survey at 1300 Sites, Crowthorne, U.K.: Road Research Laboratory, 1968 (RRL Report LR 206).

Description of a second national traffic survey conducted in Great Britain in 1966-67, using a new selection of 1297 roadside boints following the same general procedures as the 1959-60 survey (see C5) and retaining a large proportion of the earlier points; the new sample design contained 132 strata from 12 geographic divisions and 11 road types 202,079 miles in total length in 19156; some difficulty resulted from the fact that the detailed maps used averaged 10 years old; 2 or 3 16-hour counts were made at each point. The survey found that 1966 urban traffic had increased $50 \%$ and 1966 rural traffic had increased $44 \%$ compared to 1960.

C8. Transportation Research Board, "The Maine Facility; Instrumented 2-Lane Highway Generates Continuous Information on Driver Behavior", Transportation Research News 57:5-10 (Winter 1974).

Describes a 15-mile segment of U.S. 2 which has traffic counters every 200 feet and on main side roads; the collected data are being used for detailed analysis of the problems of a rural highway.

C9. Transportation Surveys Section, Michigan Department of State Highways and Transportation. Michigan Traffic Data, August, 1977: Report No. 65, Lansing: MDSHT, 1977.

A monthly report showing daily traffic counts for the month at Michigan's 108 permanent traffic recording stations (of which 97 were functioning in August 1977); counts are obtained by high frequency sound, magnetic, or loop vehicle detectors; except for two tape pickup stations where hourly counts are not available, hourly counts from rural stations are telemetered to Lansing via switched WATS lines, while quarter hour counts at urban stations are stored locally in mini-computers and telemetered to Lansing over state leased lines. At least one permanent station is located on roads in 11 of the 15 classes used by FHWA for reporting vehicle miles traveled.

(In an interview Melvyn Keesler of the Trarsportation Surveys Section provided further information as to how the annual VMT estimates for various classes of trunkline roads in Michigan are arrived at. The Section obtains about 16,000 traffic counts annually using its 350 portable counters to supplement the permanent counter information; these include $3-4$ counts at 1000 seasonal stations 
each covering at least two weekdays and one weekend day, and about 12,500 counts at other locations usually covering at least 48 weekday hours. The permanent station data is used to adjust these short counts to annual average ADT estimates, the best available ADT estimate is determined for every segment of trunkline roads, and these data are translated to annual VMT by multiplying by the segment length and by 365 days. Determination of the locations of the permanent, seasonal, and coverage count stations is based on planning needs, not on any random or probability sampling scheme. The Section also periodically carries out manual classification counts of vehicle type ( 8 categories in the most common scheme, but even more detailed classification is sometimes done) at various locations, and conducts the truck weight study for FHWA every summer. The temporary traffic counting program is carried out primarily in the summer, while the classification counting is done mostly in the winter.)

C10. Yoo, C.S. and M.L. Reiss. A Sampling Procedure Utilizing MultiState Traffic Records to SeTect Accident and Exposure Data Collection Sites, Falls Church, Va.: Biotechnology, Inc., Jan. 1977, 17 pp.

Briefly describes the methods used for selecting 80 roadside segments on six road classes in each of six states to collect large truck exposure and accident data for one year; stratification of segments by previous large truck accidents was used in the selection process. 
D. USE OF ON-ROAD MEASUREMENTS AND OBSERVATIONS

D1. Baker, Milton. "Unattended Field Measurement Instrumentation", paper presented at Automobile Engineering Meeting, Toronto, Oct. 21-25, 1974; Warrendale, Pa: Society of Automotive Engineers, No. 740940 .

Discussion of the design requirements and operation of two types of level detector recording devices developed for unattended data collection in customer cars for six months.

D2. Forde, M.C. and R.M. Birse. "The Use of Time-Lapse Cinematography for the Moving Car Observer Method", Traffic Engineering and Control 18(3): 103-105 (March 1977).

Describes a procedure using a time-lapse camera with a tape recorder to replace two crew members as part of the moving car observer method of measuring traffic volumes and average speeds on road sections.

D3. Johnson, T.M., D.L. Formenti, Richard F. Gray, and William C. Peterson. "Measurement of Motor Vehicle Operation Pertinent to Fuel Economy", Paper presented at the Automotive Engineering Congress and Exposition Detroit, Feb. 24-28, 1975; Warrendale, Pa.: Society of Automotive Engineers, No. 750003.

Report of three methods of collecting vehicle use data by vehicle instrumentation and observation all of which were used by General Motors Proving Ground in the spring of 1974 .

(1) Three chase cars were instrumented and deployed in 12 areas of the U.S. where they followed randomly selected moving passenger cars (usually for the entire remainder of its trip) duplicating its driving behavior as closely as possible; the transducer automatically recorded time, speed, ambient temperature, turn signal status, and brake 7 ight status; the second crew member manually recorded information on vehicle type and occupancy, age and sex of driver, road conditions ( 14 road types, 7 population density types, 8 traffic density types, etc.), and environmental conditions using panel switches; over 2500 trips were monitored covering 11,000 miles of operation.

(2) Long duration strip-chart recorders were installed in 6 private GM intermediate cars for approximately 2 months; these devices recorded traces of speed versus time over 12,000 miles of vehicle travel. 
(3) Electronic recording devices were iristalled in 20 private GM intermediate cars (including the above 6) which record the number of miles driven within $10 \mathrm{mph}$ speed bands; over 61,000 miles had been logged at the time of the report.

D4. Lincorp Research, Inc. Southfield, Mich. (Michael Dworkin, Pres.) Uetroit Area Seat Belt Use Survey (report not yet published) 1977.

This study involved an elaborate semi-probability-based selection of 224 Detroit area intersections with stop signs or traffic signals; at the selected intersections one corner was chosen and driver seat belt use was observed by a team of two observers for a11 cars stopped in the right curb lane for one daylight hour during a 14day period; over 20,000 observations were carried out at these sites before and aga in after the special seat belt use campaign carried out by Motorists Information, Inc. in the fall of 1977 ("Somebody Needs You").

D5. Murphy, Gary L. "The Use of a Photographic Detection System for Counting and Classifying Vehicles on Forest Service Roads" in New Developments in Optical Instrumentation - A Problem Solving TooT in Highway and Traffic Engineering, Washington: Society of Photo-Optical Instrumentation Engineers, 1973 (Proceedings, Vol. 37).

Report of the trial use of a digital clock and a timelapse camera actuated by movement past an infrared sensor in order to count and classify vehicle and pedestrian use of a low volume forest service road (approximately 100 ADT); problems encountered included false triggering caused by passing shadows, malfunctioning in cold weather, missed vehicles due to incorrect camera angle, inability to obtain pictures at night or in heavy precipitation, infeasibility of concealing the camera and thus pilferage and vandalism; at two frames per vehicle up to 1800 vehicles could be observed on a 50-foot cartridge, thus usually requiring only once a week maintenance and film replacement. The author feels that the main problems can be solved and that there is a useful future for this observation method.

D6. Peterson, John R. "Vehicle Field Data Collection", paper presented at the Automobile Engineering Meeting, Toronto, Oct. 21-25, 1974; Warrendale, Pa: Society of Automotive Engineers, No. 740941.

Brief discussion of General Motors' insertion of various types of self-powered recording instruments in the trunks of samples of customer cars as unobtrusively as possible (no mention of compensation of the participants of of the quantity of such insertions); the devices allow unattended data collection for 4 months. 
D7. Josslau, Arthur B. and Gary E. Houts. "Traffic Characteristics Measurement Using License Matching Techniques", Traffic Engineering 45(10): 16-21 (Oct. 1975).

Description of a procedure for measuring speeds and traffic volume over a section of highway by observer recording of 3 digits of the license plate numbers of the passing vehicles at each end of the road section and then matching them by computer; two recording procedures were tested, one using a voice tape recorder which required subsequent listening and keypunching, and the other using a touch-tone cassette with built-in clock with recording directly on machine-readable magnetic tape; the latter equipment was much more expensive and also somewhat slower and more error prone, but saved a lot of manual transcription time, and would be recommended for an extensive on-going program; alphabetic characters in license plates caused more difficulties than numeric characters by both methods; the use of one observer per lane was recommended, usually reading the front license plate.

D8. Thompson, Glenn and Miriam Torrez. Environmental Protection Administration Study of Vehicles in Use (projected-no publication yet).

During 1978 EPA expects to conduct a feasibility study of instrumenting a sample of cars in one city (probably Portland, Ore.) for a period of 2 weeks each; data recorded will include time, mileage, brake applications, speed, shift points, etc.; also there will be a switch by which the driver can indicate when he or she changes from a rural to an urban environment and vice versa.

D9. Hutchinson, John W., R. Vince Sayre, John A. Dearinger, et al. Recreational Vehicle Accident Investigation Study: Interim Report, Lexington: University of Kentucky Multidisciplinary Accident Study Team, 1975.

Describes a method for determining accident rates for 10 classes of recreational vehicles and comparing these with overall vehicle accident rates to obtain relative measures of risk; the accident data will come from supplemental forms filled out on Kentucky recreational vehicle accidents over a two-year period; the exposure data will come from manual classification counts carried out once or twice a season for 18 months on 8 road segments for 8 to 24 hours on a weekend and sometimes on weekdays; these counts will then be used along with toll road revenue reports from ten Parkway segments and automatic traffic recording data from 13 permanent count segments to project annual VMT for each class of recreational vehicle (estimation method not explained). 
D10. Paulley, R.J., N. Taylor, and D.A, Walmsley, A Survey of South bound Motorway Trave1 on the MT and M6 in 1974, Crowthorne, England: Transport and Road Research Laboratory, 1977 (TRRL Report 786).

Report of a time-lapse photographic survey of vehicle registration numbers at four points on the corinecting $M 6$ and M1 motorways; $35 \mathrm{~mm}$ cameras were set up on tiridges to shoot oncoming traffic at 1 frame per second using a long-focus lens to record registration numbers at a distance of several hundred yards, usualiy 3 or 4 pictures of each vehicle were taken; the filming was on June 4, 1974, during daylight only; film had to be changed about every 100 minutes; only about $1-5 \%$ of the vehicle registrations could not be transcribed, but coding checks found that another $10 \%$ of the registrations were miscoded, still substantially less than the error rate of a pilot test in which registration numbers were entered verbally into a tape recorder and then transcribed. The survey data were then used to obtain matched traffic flows by vehicle type between the various observation points. 
E. USE OF ON-ROAD OBSERVATIONS WITH FOLLOW-UPS

El. Boek, Jean K. "Driver Behavior and Accidents", American Journal of Public Health 47:546-552 (May 1957).

Describes briefly an observational study of 550 drivers in Schnectady, N.Y., on weekdays; used 100 randomly selected intersections and followed selected cars for 1-2 miles recording license number, age, sex, and the safety of nine possible driving actions; then checked driver record data for age and sex of owner and if not the same contacted the owner for an accurate age of the driver; found no relationship between judged safety of driving acts and accidents.

E2. Maring, Gary and Howard McCann. "License Plate Traffic Survey", in Highway Planning Tech nical Report No. 8, Washington: FHWA, 1968.

Discusses the recording of license plates at roadside locations, matching these with computerized registration records, and using a postal survey to obtain information about the sampled trip. As used in Boston a $65 \%$ return rate was obtained from in-state respondents and a $60 \%$ return rate was obtained from out-of-state respondents.

E3. Maring, Gary and Howard McCann. "Application of Automated Vehicle Registration Files to Postal Origin-Destination Surveys", in Highway Planning Technical Report No. 11. Washington: FHWA, 1969.

Discusses a Kansas study using license plate numbers recorded at roadside locations and a postal survey--response rate $53 \%$. 
F. USE OF ROADSIDE INTERVIEWS

F1. Brant, Jr., Austin E. and Dana E. Low. "Cost-Saving Techniques for Collection and Analysis of Origin-Destination Survey Data", in Origin and Destination Characteristics: 8 Reports, Washington: Highway Research Board, 1967 (Highway Research Record Number 205).

Suggests that better quality and cheaper roadside interview data can be obtained by careful formulation of the interview schedule, by using clear and simple vehicle sampling techniques, and by sampling vehicles in the inbound direction only at the cordon stations around the study area.

F2. Hajek, J.J. Optimal Sample Size of Roadside-Interview Origin-Destination Surveys, Downsview, Ont.: Ministry of Transportation and Communications, January 1977.

The data analyzed were collected at 3 stations in the 1971 Niagara/Lake Erie Transportation Study over 12-hour periods using an "interview as many as you can" sampling procedure; actual sampling rates varied from $64 \%$ to $95 \%$. The author compares observed with theoretical root-meansquare errors (RMS) and concludes that more rigid predetermined sampling procedures are possible (references are given) but would result in little improvement in sampling error, that at bidirectional sampling rates above $50 \%$ it would be more cost-effective to error reduction to extend the survey hours (to reduce the factoring error in expanding to 24 hours) than to increase the sampling rate, and vice versa for bidirectional sampling rates of $30 \%$ or less, etc.

F3. Solomon, David. Accidents on Main Rural Highways Related to Speed, Driver and Vehicle, Washington: Bureau of Public Roads, 1964, 44pp.

Report of a massive exposure study of 35 main rural road sections totaling 600 miles in 11 states in 1957-58, 27 2-1ane and 8 4-lane divided (but only 1 limited access). These road types account for about $1 / 3$ of U.S. VMT. On each section a representative site was selected where traffic moved at a rate average for the whole section; 290,000 drivers had their speeds measured by concealed devices at these sites and then were subsequently stopped for a short interview (doesn't say how data were linked). These data were compared with 10,000 accident involvements on these same sections over 3-4 years (although there was $21 \%$ missing data on estimated travel speed just before accident), and seasonal traffic volume data 
was used to expand exposure data to the same periods as the accident data and to adjust car ages, etc. (no explanation of how the VMT denominators were obtained). The analysis compared accident involvemert rates for all accidents, severity types, and collision types for travel speed groups, road type, speed limits, frequency of intersections and driveways, age groups, sex, driver residence (local county, other in-state county, out of state), in military or.not, vehicle type, body style, 3 horsepower groups, vehicle age, vehicle make, and occupant position. The accident data alone were analyzed using severity, day-night, type of collision, sex, age, travel speed, vehicle type, and number of vehicles. Most groups compared contained at least 30 accidents, so differences of $30 \%$ or less were significant at a $95 \%$ level of confidence.

F4. Wiklund, Tage and Lennart Forsells, "Roadside Interviewing on Motorways: A Regional Traffic Survey for Stockholm", Traffic Engineering and Control 14(4):168-169, 173 (Aug. 1972).

As part of a large origin-destination survey in the Stockholm region in 1971 15,000 interviews were successfully obtained in 4 days on the E4 motorway; the procedure involved reducing the speed of all vehicles to $30 \mathrm{Km}$ and selecting 20-40\% of the vehicles for interview in bays located in staggered locations in the two lanes; the police were somewhat skeptical but they provided traffic control services and no problems were encountered even in night interviewing; this roadside interviewing on motorways required a special dispensation from the Ministry of Transport because of the regulation prohibiting parking on motorways. The fuli 1 study included interviews with 100,000 drivers, 100,000 public transport passengers, and 10,000 respondents at home.

F5. Wolfe, Arthur C. 1973 U.S. National Roadside Ereathtesting Survey: Procedures and Results, Ann Arbor: Highway Safety Research Institute, May 1974.

Report of a roadside survey carried out at 185 roadside locations in 24 primary sampling areas of the U.S. on Friday and Saturday nights between 10 PM and 3 AM on 8 weekends in the fall of 1973; the primary sampling areas were selected by controlled probability procedures; the roadside locations were selected by random grid or segment listing procedures on medium and heavy volume roads, but in most areas the selection probabilities could not be determined; the vehicles were selected from the passing 
traffic stream in a random manner and weighted by the total number of eligible vehicles passing during the interviewing period; 3698 drivers were stopped from whom 3192 satisfactory breath tests were obtained (86.3\%) and 3358 interviews were obtained $(90.8 \%)$; the interviews lasted 5-10 minutes and included demographic data, trip data (origin, destination, distance, time), annual mileage and night driving percentage, alcohol use information, and drunk driving knowledge and attitudes data.

F6. Carlson, William L. "Age, Exposure, and Alcohol Involvement in . Night Crashes", Journal of Safety Research 5(4):247-259 (December, 1973).

Describes the use of a roadside breathtesting survey in Washtenaw County to estimate driver exposure during three nighttime periods by age and drinking condition of the driver; the percentages of drinking drivers of different ages are then compared with the percentages of nighttime single-vehicle alcohol-related crash drivers of different ages to obtain indicators of over or under involvement for specific ages; the same procedure is repeated for a number of other comparisons of interest. The author finds that 16-18 year old drivers are overinvolved in nonalcohol-related nighttime crashes and that 18-27 year old drivers are overinvolved in alcoholrelated nighttime crashes.

F7. Interstate Commerce Commission. Empty/Loaded Truck Miles on Interstate Highways During 1976, Washington: ICC, ApriT 1977.

Report of a nationwide roadside survey of trucks having 3-or-more axles driving on Interstate Highways during all of 1976; for sampling, the Interstate Highway System was divided into 221 segments ranging in length from 28 to 652 miles, and roadside samples were stopped for one hour in each direction during each quarter of the year; the sampling hour in one direction was selected randomiy and in the other direction was 2 hours later; out of an expected 1768 samples 1653 samples containing 13,165 interviews were actually collected, an average of 8 interviews per sample hour out of an average of 40 passing trucks per sample hour; interview locations were mostly established weigh stations or rest areas or state port of entry checkpoints, but a few were just on the road shoulders. Data collected included body type and length, type of carrier, first origin, last destination, commodity, extent loaded, and weight (estimated at locations without scales). (The heaviest truck sampled was a 160,640 ib. Michigan 11 -axle tank truck carrying slag; the heaviest net weight 
was 114,000 pounds of coil steel on a Michigan flat bed truck.) It was estimated that overall $20.4 \%$ of truck miles on the Interstate System are operated empty and another $14.4 \%$ of the miles are operated below caplacity. $(38,0 \%$ empty for tank trucks). 


\section{G. USE OF. HOME IN-PERSON INTERVIEWS}

G1. Boek, Jean K. "Driver Behavior and Accidents", American Journal of Public Health 47:546-552 (May 1957).

Report of a home interview study of a random sample of 810 drivers in Schnectady, N.Y., analyzing the relationship of 60 characteristics to accident history; found exposure over $2 \frac{1}{2}$ years (six mileage categories) and sex (fewer female accidents) related to accidents but few other relationsihps with exposure and sex controlled; also asked the respondents to keep a daily record of miles driven for the four weeks following the interview and recontacted the respondent each week to obtain these daily mileages, but no use of these data is reported.

G2. Dawson, R.F.F. and J.G. Wardrop Passenger-Mileage by Road in Greater London, Harmondsworth, U.K.: Road Research Laboratory, 1962, 29 pp. (Road Research Technical Paper No. 59).

A report on a household interview exposure survey made in Greater London Jan. - April 1954 with results adjusted to 1958; over 11,000 persons aged 3+ were asked to describe all journeys made in the 7 days before the interview day except trips on foot and as commercial drivers - about a $70 \%$ response rate. About $47 \%$ of the trips were non-regular (casual) and reporting of these fell off drastically as the recall period lengthened (from average of .44 on previous day to .187 days previous). Origins and destinations were recorded by half mile square grids and used for estimating distances. Analysis includes comparisons of travel mileages by type of vehicle, time of day, trip purpose, in and out of working time, day of week, income, and length of trip categories.

G3. Federal Highway Administration. 1969-70 Nationwide Personal Transportation Survey, Reports 1-11, Washington, 1972-74.

This series of reports presents analyses of the data collected in a household interview survey conducted by the Census Population Survey using two outgoing panels from the Quarterly Housing Survey each containing 3000 households; travel day and overnight trip information was obtained for all household members aged five or more four times for the first panel (April, July, October, and January) and once in August for the second panel; the Travel Day for a particular household was a randomly selected day in the previous week; the information collected included 
trip beginning time, distance, duration, purpose, companions, trip means, vehicle used, and parking cost; in addition, at the first interview in each household information was obtained about household vehicles including age and estimated annual mileage, CBD shopping, 1 icensed drivers and estimated annual mileage (in $5000 \mathrm{mi}$. categories), travel to work for those over 16, and travel to school for those 5-18.

G4. Federal Highway Administration, 1977-78 Nationial Travel Survey, reports forthcoming from survey currently in process.

This household interview survey being conducted by the Census Population Survey for the Department of Transportation involves Travel Day collections from 19,000 households in April and January, plus 2 or 3 collections during intervening months and Travel Day collections from 6,000 households in December or February or March; in addition 6,000 other households will be interviewed four times concerning trips over 75 miles in a designated 14 day period; interviewing is to take place as soon as possible after the designated Travel Day for a household and no more than 4 days later. The information collected on Travel Day trips includes destination, origin, beginning time, purpose, household companions, distance, duration, means, vehicle used, non-household companions, driver(s), parking, availability of public transportation, reasons for use or non-use of public transportation, movement within CBD or not, and movement across a rural/urban boundary and mapping of such trips (or general route description for long trips not all on the local map). Other information collected concerns household vehicles and licensed drivers (including annual mileaqes in thousands), availability of public transportation, and travel to work. Proxy information is not acceptable for the travel behavior of household members 14 and over, and interviewers are urged to use the telephone for callbacks on persons not available during the initial interview. Trips to be reported include bicycle and walking trips for persons 14 and over.

G5. Fresno-Clovis Area Transportation Study. Volume II - Origin and Destination Survey 1971, Fresno: Council of Fresno County Governments and California Division of Highways, 1973.

A report of a typical origin-destination study in California involving a two-contact procedure for collecting a probability sample of household interviews and a roadside interview of samples of cars and trucks passing out of the study area on weekdays between 6 AM and 8 PM at 36 of 79 cordon stations ( $p l$ us weekdays at 7 stations); the household interview collected detailed information on all automobile, bus, 
and truck trips on a designated Travel Day and involved a prior contact leaving a simple trip record form and a full interview as soon after the Travel Day as possible; there were 7181 "samples" in the household survey, but no response rate information was provided; interviewers were hired and trained locally under Division of Highways and supervision.

G6. Lansing, John B. and Gary Hendricks. Automobile Ownership and Residentlal Density, Ann Arbor: Institute for Social Research, 1967.

The last of four reports based on two waves of a national survey of residents of metropolitan areas (except New York City) in 1963 and 1965; the study focuses particularly on the journey to work of employed household members, but also asks about all trips the day before the interview by persons aged 5 or over including origin, destination, purpose, and means; questions were also asked about number of household vehicles and age and average annual mileage and total mileage of each vehicle. The average household annual mileage was 13,000 miles, and for the $83 \%$ of the families with at least one car it was 15,800 miles; there was a close direct linear relationship between total mileage and family income, and there were also relationships found between mileage and residential area (older central cities, newer central cities, suburbs) and between mileage and age of family head (inverted U-shaped curve).

G7. Lansing, John B., Robert W. Marans, and Robert B. Zehner. Planned Residential Environments, Ann Arbor: Institute for Social Research, 1970.

Report of a study of 10 committees selected to represent different levels of planning concerning community satisfaction and transportation requirements; included were questions about all trips the previous day by household members aged 5 and over covering origin, purpose, destination, and means. In each selected household the head or wife was randomly designated as the appropriate respondent for the entire household in advance of the interview; when the trip data from the married couples was analyzed it was found that husbands reported an average of 11.5 person trips per day while wives reported an average of 10.4 trips per day; in particular husbands reported an average of 4.61 trips for themselves while wives reported an average of 3.75 trips for their husbands; thus there seems to be a substantial bias in using the wife's trip report data for the husbands. 
G8. McMillan, Robert K, and Henry Assel, National Survey of Transportation Attitudes and Behavior: Phase 1 Summary Report, Philadelphia: Chilton Research Services, 1968 (National Coopeirative Highway Research Program Report 49).

Reports the results of two independent national household interview surveys in 1967 (each with 2500+ respondents aged 18+) concerning att tudes toward and use of the automobile, highway facilities, and public transportation. Includes data on household car and other motor vehicle ownership, years licensed, annual miles driven in household vehicles and rental cars, usual transportation method for long and short trips, purpose and method and distance of all trips taken yesterday and the day before yesterday, percentage distribution of total vehicle miles among 5 purposes, and personal annual mileage by 5 modes (auto, train, air, intercity bus, and local public transportation). Average annual mileage was 12,000 ; average number of weekday trips was $3 \frac{1}{2}$ and average number of weekend trips was $2 \frac{1}{2}$, with 3 miles the average distance for both; $85 \%$ of trips were by auto; $17 \%$ were for Dusiness or work; $46 \%$ of total miles traveled were for work or business ;and $78 \%$ were by auto (trucks not shown as a separate category).

G9. Munden, J.M. "The Accident Rates of Car Drivers by Age, International Road Safety and Traffic Review 14(1):28-29 (Winter 1966).

Uses driver annual car mileage estimates from the 1961 survey of private motoring in England and Wales to obtain percentages driven by eight age groups, applies these percentages to the national estimates of vehicle miles traveled based on the Road Research Laboratory's 50-point and 1000-point censuses in order to obtain annual VMT by age group, and compares accident involvement rates by age group; the results show the familiar $U$-shaped curve with the highest rates in the under 20 group and another but lower peak in the $70+$ group. Mentions that the survey also obtained a 7-day travel log (not clear if retrospective or prospective) and that the percentages based on annual estimates were quite similar to those based on weekly totals.

G10. Pelz, Donald C. and Stanley H, Schuman. Exposure Factors in Accidents and Violations of Young Drivers, Ann Arbor: U-M Highway Safety Research Institute, 1971 . 
An analysis of an in-person household survey of about 3000 drivers in Detroit suburban areas, mostly young males 16-24 (1651) but also including females 16-24 (468), males 35-44 (300), and females 35-44 (314); data were collected in four seasonal waves to cover an entire year; exposure data included estimated annual mileage, monthly trips to school and work and on errands and typical mileages, long out-of-town trips in past year, short out-of-town trips in past month, hours spent each week driving to work and school and on errands and for fun, percentages of driving during three time periods, and percentages of driving on four types of roads; the dependent variables were the numbers of infractions (self-reported and officially recorded accidents, and moving violation tickets and warnings). After adjustment by multiple classification analysis only two exposure factors showed significant relationships to accidents, total mileage and low driving in heavy city traffic, while six factors were significantly related to violations and warnings for young males; however, the exposure variables explain only a small percentage of the variance in accident rates for any of the four groups; the data show a logarithmic rather a linear relationship between total mileage and both types of infractions.

G11. San Diego County Comprehensive Planning Organization. Transportation Study: Manual of Instructions for Home Interviewers, April 1977.

This manual describes a two-contact procedure for gathering trip information over a 3-day period; a household is assigned a Travel Day on which all trips of household members aged 5 or more are to be reported (including walking $\frac{1}{4}$ mile or more), the interviewer contacts the household the previous day and leaves a simple trip record form for each household member to keep track of the origin and destination and times of each trip made, and the interviewer returns the day after the Travel Day to obtain detailed information about all trips using the trip record as a reminder. Other trip information includes mode, purpose, number of occupants, household vehicle used, parking type and cost, and public transportation cost and transfers and waiting time. If the interview with some household members cannot be satisfactorily completed within 2 days after the Travel Day then the same day of the week 7 days later is substituted and the procedure is repeated. Vehicle information collected includes make, model, year, number of cylinders, and average miles per gallon. Each interviewer was expected to conduct 4 household interviews per day and was instructed to make up to 3 contact attempts after 3:00 PM on the day before the Travel Day. 
(A cal! to Wes Frysztacki of the San Diego County CPO was unable to elicit a definite response rate but he said it was "quite high". He said the CPO hired and trained their own interviewers, mostiy mid-aged women with experience working with people, and paịd them quite well $(\$ 4.5 \mathrm{C} / \mathrm{hr})$. He estimated costs at about $\$ 20$ for each of the 1000 households in the sample. The same methodology had been used in a similar study in San Diego in 1966.)

G12. Taylor, Louise and Lol1ta Len. The Travel Behavior and Mobility Patterns of Low Income Residents of Syracuse, New York, paper presented at the Transportation Research Board Fifty-fifth Annual Meeting, Washington, January 19-23, 1976.

A brief report on a survey of 50 autoless $A D C$ recipients in Syracuse; each respondent was shown how to complete a detailed travel diary on three self-selected travel outings and was interviewed after the diary was completed; of 359 trip segments reported 144 were as car passengers, 19 were as drivers in borrowed cars, 109 were by bus, 78 were by walking, and 8 were by $\operatorname{tax} i$. 
H. USE OF LICENSE RENEWAL OFFICE INTERVIEWS OR QUESTIONNAIRES

H1. Burg, ATbert The Effects of Exposure to Risk on Driving Record, Los Angeles: UCLA Institute of Transportation and Trafflc Engineering, June, 1973 .

An analysis of licensing office interview and driver record (3 year or 6 year) data for over 12,000 California drivers found estimated annual mileage to be the factor most correlated with numbers of accidents and numbers of violation convictions (correlations of .178 and .322 respectively for 7020 drivers with $6 \mathrm{yr}$. records). Factors correlating with accident rate include age $(-.072)$, \% city street driving $(.070), \%$ freeway driving $(-.047)$, peek hours driving $(.042)$, \% rural road driving $(-.041), \%$ nighttime driving $(.035)$, and \% occupational driving $(-.063)$. Age also correlates negatively with both accident and conviction rates $(-.072$ and -.174 respectively), as does annual mileage $(-.133$ and -.137$)$-that is, while the number of accidents increases with increased annual mileage the accident rate decreases. Multiple regression of 17 variables with number of accidents (Table C-3, Col. 5) was .277 with annual mileage the best predictor, unmarried second, maleness third, fewer yrs. driving fourth, \% pleasure driving fifth (negative), $\%$ rural road driving sixth (negative), and \% of nighttime driving seventh. The $R$ for accident rate using the 9 driving type variables plus sex (age and marital status not included) was only .102 with \% city street driving the best predictor, $\%$ occupation driving (negative) second, \% daytime driving (negative) third, and peak hours driving fourth (Table C-7, Col. 7); sex was insignificant.

The study recommends inclusion of estimates of annual mileage and proportions of night and occupational driving along with vehicle types used on regular license renewal applications.

H2. Carroll, Philip S., William L. Carlson, Thomas L. McDole, and David W. Smith. Acquisition of Information on Exposure and on Non-Fatal Crashes, 6 volumes, Ann Arbor: U-M Highway Safety Research Institute, 1971.

Describes two licensing office surveys conducted for NHTSA in 1969-70. The preliminary survey consisted of personal interviews with 448 drivers who renewed their licenses in August 1969 in Washtenaw County, Michigan; along with detailed data on the two vehicles driven most and on thejr personal background respondents were asked to estimate the number of miles driven in each vehicle in the past 7 days, how much each vehicle was used for 5 different purposes and on 6 different types of roads, how much driving was done in different light, weather, and occupancy conditions, and their accident and violations history for 3 years. 
The pilot survey took place at 37 licensing offices in 32 sampling areas in 18 of the 24 states which then required a personal appearance for 1 iccense renewa 1 ; local interviewers were hired from temporary-help organizations; out of 10,000 expected respondents 8014 were actually selected on a systematic sampling Dasis in the 37 offices and 7145 participated in the interview, an $89.75 \%$ response rate; in each location the interviewing took place for a period of 9-20 days between Jan. 15 and June 15, 1970; the questionnaire was similar to the preliminary survey questionnaire except that the respondents were asked only about the most used vehicle, fewer road type and weather conditions categories were used, some personal and vehicle questions were dropped, and past month's estimated mileage was asked as well as the past week's mileage.

H3. Lee, Martin and Arthur C. Wolfe. 1976 Michigan Driver Exposure Survey (survey completed but no publications yet).

This survey sponsored by the Michigan Department of State and planned and coordinated by the Highway Safety Research Institute was carried out throughout 1976 in 30 licensing offices chosen by a controlled probability procedure; different sampling ratios of renewal applicants were established depending on the expected volume so that 2-3 applicants would be interviewed by the office managers or their deputtes every day (the actual respondents were pre-designated by the last two digits of their application form number); out of an expected 10,606 respondents 9045 were actually contacted and 7721 provided interviews $(85.4 \%$ of those contacted). Respondents provided estimates of their annual and past week's driving mileage; basic information on vehicles used in the past week; other vehicles in the household; bicycle use; details of all trips driven on one of the previous three days (origin, destination, purpose, time, lights, duration, stops, distance, 5 road types, vehicle used, passengers, and availability of public transportation); and personal background. (One trip was defined as a complete journey with no single stops of more than one hour).

H4. Stewart, J. Richard. An Analys is of Annual Mileage Self-Reported by Renewal Applicants, Chapel Hill: University of North Carolina Highway Safety Research Center, about 1973. (This study is also reported in Section 3 of Improved Exposure Measurements: Final Report by the Research Triangle Institute, 1976.

Discusses the data from a self-administered questionnaire filled out by renewal applicants throughout North Carolina during 7 days in January 1973 in conjunction with the evaluation of new written driver license examinations; usable information on age, sex, race, and estimated annual driving mileage was 
obtained from 12,695 drivers; other information obtained from most of the applicants included education, occupation of self and parents, driver education, type of yehicle usually driven, annual and past week's mileage in that vehicle, past week's total mileage and percentage between midnight and 6:00 AM, and involvement in an accident in the past year. In the analysis driver record data for the previous 4 years was combined with the questionnaire data to obtain accident rates in $8 \mathrm{age} / \mathrm{sex}$ classes by four annual mileage groups. 


\section{USE OF TELEPHONE INTERVIEWS}

I1. Campbel1, E. Q'F. "Investigation of Exposure to Risk Factors Among Young Drivers (16-25 Years) 1969-1971," Canadian Journal of Public Hea th 63(6):504-507 (Nov.-Dec, 1972)

Report of a study by the Traffic Injury Research Foundation of accidents and violations in relation to exposure in a subject sample of 2000 vancouver drivers aged 16-25 and a control sample of 2000 drivers aged 42-51 (in matched pairs on sex and residential location). Used primarily telephone but some face-to-face interviews to obtain detailed information about the most recent 24 hours of weekday driving, about usual and unusuā 7 weekend driving, about vacation motor trips, and about estimated annual mileage. Information was obtained from 759 subjects and 733 controls. Male controls averaged higher annual VMT (8076) than male subjects (7070), while female subjects averaged higher (3425) than female controls (2737). Male subjects had about $60 \%$ more accidents per mile than male controls, and female subjects had about $25 \%$ more than female controls. Male subjects had twice as many violations per mile as male controls, but female subjects had slightiy lower violation rates than female controls. However looking at the teenage subjects separately one finds the teenagers with a $20 \%$ lower accident rate than their controls, while the subjects in their twenties have twice the accident rate of the controls.

12. Clark, III, J.E. and D.A. Morin, "Securing Travel Data by Telephone Interviews", Traffic Engineering 36(9):47-49 (June 1966).

Reviews some previous studies using the telephone to obtain travel data; reports a successful pilot study of 60 households in Salem, Oregon (response rate 93\% - a letter from the Mayor with trip log forms was sent prior to the telephone interview); and provides preliminary data from the 1965 Spokane Metropolitan Area Transportation Survey showing very comparable findings for the telephone interview method compared to the conventional home interview method. Concludes that telephone interviewing has the advantages of cost savings, greater ease of obtaining firsthand trip reports, greater ability to make many calls and at various times thus improving the response rate, and easier supervision and monitoring.

I3. Pendakur, V. Setty, "Origin-Destination Studies - The Telephone Technique", Traffic Engineering and Control 8(7):448-451 (1966).

Report of a trip survey in Prince George, B.C.; 1200 homes were telephoned in the evening (200 each day Monday through 
Saturday) and asked about motor vehicle ow'nership, work travel means, and trips made between 3 and 7 PM on the same day; extensive pre-survey publicity was used, and the refusal rate was less than $1 \%$ while no answer on the first call was only $5 \%$; the total survey required only 12:0 person hours:-

14. Rappeport, Michael and Patricia Labow. Automotile Usage Patterns Highlight Report: Vo1. XIV, Princeton: Opinion Research Corporation, 1975.

A brief report of a summer 1975 telephone survey (probably using Random Digit Dialing) of 1007 resporidents aged 18 or more; little methodological information is included but apparently respondents were asked about automobile trips made during some short period: distance, purpose, planned or routine or spontaneous, frequency per week, possibility of going only once a week, degree of enjoymerit from trip purpose, availability of public transportation, possibility of combining trips for different purposes, degree of necessity of the trip, degree of willingness to cut out the trip to save gas, degree of willingness to cut out the trip to save money on gas, and whether would have still made the trip if gas cost 704 a gallon or if gas were rationed to 10 gallons a week or if it took one hour in line to buy gas. Every single respondent had made at least one automobile trip in the previous week. 
J. USE OF MAIL QUESTIONNAIRES

J1. Bygren, Lars 01 av "The Driver's Exposure to Risk of Accident", Scandinavian Journal of Social Medicine 2:49-65 (1974) (Dept. of Social Medicine, Karolinska Institut, Stockholm).

Report of a mail survey to 3 age-stratified samples of urban (Stockholm), suburban (4 areas outside Stockholm), and rural (4 areas of 0stergotland County) registered residents born 1876-1949. The original sample totaled 22,575; response rates were: Urban 10995/12984=85\%; Suburban 4428/15445=81\%; Rura1 $3767 / 4146=90 \%$. Average sample age was lower in suburbs + higher in city - also more female and singles in city; $90 \%$ of responses described driving in a week in May 1965 - the other 10\% second-chance respondents described a week in June; 2 reminders were sent out at end of each week; some supplementing phone calls were made for missing information (the national traffic was heavier in June weeks $(153 \mathrm{M} \mathrm{km}$.) than in May weeks (137 M, $138 \mathrm{M})$ ).

The questionnaire included 1964 mileage by moped, motorcycle, car, truck, etc.; miles driven during each of 42 4-hour periods over one week; \% of week's mileage by 3 purposes; urban-rural areas; employer's or other car; with and without passengers; type of driving license; and when got first license.

Poorer male response rates than female, age 36-45 lowest in both sexes. Interviewed 196 of a sample of 262 nonrespondents of the 64 remaining 20 could not be traced, 39 couldn't be reached, and 5 were dead - particularly unavailable were young men and women and men up to 45; found a somewhat greater average mileage per driver for the nonrespondent group (17.5K) than for the $3+$ reminder group $(13.4 \mathrm{~K})$ and for the easy respondents $(0-2$ reminders $)(12.6 \mathrm{~K})$.

32. Carroll, Philip S. Driver Exposure Survey: A Field Test of the TripLog Method, Ann Arbor: U-M Highway Safety Research Institute, 1974.

Reports the results of a mail questionnaire sent to 10 randomly selected Michigan drivers every day throughout 1973; the accompanying letter was from the Director of the Michigan Office of Highway Safety Planning; the trip-log form asked for the driver's age and sex and for detailed information about every trip made on a designated future day (vehicle type, make, model, and year; beginning and ending odometer readings; and estimated day/night miles and miles on four types of roads); if the trip information was not recorded on the designated date ( 8 days after mailing) the respondent was instructed to use it 
on some other date of his own choice, but how often this was done is not reported; about $9 \%$ of the questionnaires were returned undelivered by the post office; excluding these from the sample the 959 returned trip-logs provide a $30 \%$ response rate; no identification data were requested and no follow-up procedures were attempted. Even though 2:3\% of the respondents reported no driving on the designated day, the overa 11 average daily mileage was considerably higher than the average estimated by the Michigan Department of Highways. These exposure data and a file of 1973 Michigan accident:s were analyzed in 18 exposure classes using six variables (sex, vehicle type, model year, age, road type, and day/night), and the resulting accident rates for these 18 classes were determined.

33. Carrol1, Philip S. Driver Exposure Survey: A Field Test of the TripLog Method, Ann Arbor: U-M Highway Safety Research Institute, 1975.

Reports the results of continuing the above "mail survey throughout 1974 using the identical procedures; 979 completed forms were obtained for a response rate of $31 \%$; in this report only exposure data were analyzed and compiared with the 1973 survey; overall the average daily mileage showed almost a $10 \%$ reduction in 1974 .

34. Foldvary, L.A., "A Method of Traffic Survey in Queensland; Design and Application, 1963", Australian Road Research 1(1):27-42 (Dec. 1963)

Explains design of the pilot study in Queensland and plans for the full study; 100 questionnaires are mailed out daily to owners of registered vehicles due to renew their annual registration (s ame mailing as the average of 1250 renewal notices sent 5 weeks before the expiration date and to be returned together) - 5 selected randomly from the daily motorcycle subregister, 5 selected randomly from the daily taxi subregister, and 90 selected systematically from the daily mixed motor vehicle subregister; this method includes vehicles which have been retired and misses vehicles newly registered within the study year; for expanding results to the whole population the return rate and the sampling fractions can be easily applied; personal interviews with a sample of nonrespondents to study bias were planned, but there wasn't enough money. Requested trip information for a particular day of the week next after receiving the questionnaire. In the pilot study they got higher returns with a questionnaire form which included the individual registration number than with a form which left it out, so it was decided to include the number plus new questions on owner's occupation and on reason for no trips and both beginning and ending times for each trip. 
35. Foldvary, L.A. "Methodological Lessons Drawn from a Vehicle Mile Survey", Accident Analysis and Prevention 1(3):223-244 (1969).

Brief description of the methods used to obtain 23,694 travel reports from owners of registered vehicles in Queensland. A sample of 100 owners was drawn daily for 18 months from the daily subregister of persons to be notified that they should reregister (about 5 weeks before the deadline). Overal1 original return rate was $36.5 \%$, which was brought up to $86 \%$ for four months in which up to two reminder letters were sent to nonrespondents. Comparisons of the original and reminder returns were used to adjust 8 of 89 classifications. Two types of questionnaires were used in the second half of 1963, one with and one without registration number, and the former got the higher original response rate (33.7 to 30.3). In 1964 a third questionaire was used which asked some more personal information and it got a $37.9 \%$ original return $(40.3 \%$ in the first 6 months, $34.7 \%$ in the second 6 months). Thus season seemed quite significant in return rate. The travel reports were assigned to a particular future day of the week but not to a specific date, and asked about each trip of the vehicle on that day including times, origin, destination, purpose, occupants, and age and sex of driver.

36. Foldvary, L.A. "Road Accident Involvement Per Miles Travelled - I, II, III", Accident Analysis and Prevention 7(3):191-205 (Sept. 1975), $8(2): 97-128$ (June 1976), 9 1):27-54 (March 1977).

Report of the results of an 18-month survey of registered motor vehicles in Queensland, Australia, during 1963-64 involving sending a mail questionnaire to 100 owners daily and asking them to fill out a vehicle use questionnaire for one designated future day of the week. With two reminder letters an $87 \%$ response rate was achieved. Information collected included vehicle type, owner occupation, and for each trip the driver age \& sex, beginning and end times, distance, purpose, occupancy, and for commercial vehicles weight and load. The study also collected data on 27,000 1961 accident involvements in Queensland, and using the vehicle trip data as the denominator analyzed differences in accident rates for a large number of cross-classified variables, e.g., 12-2 AM, had an overinvolvement rate of 6.77 compared to other 2 -hour periods, Saturday had an overinvolvement rate of 1.34 compared with other days of the week, etc. The second section reports accident rate analyses of other variables(some cross-classified) such as occupancy and seat position, vehicle type ( 3 categories), brake horsepower, braking surface area, vehicle weight, car 
collision type ( 3 categories), accident severity (2 categories), and geographic area (Brisbane metro, other urban, rural) includes evidence that rear seats are safer than front seats especially in single car accidents (outboard passenger seat least safe). The third section adds analyses of vehicle type by area (commercial vehicles safer overall but not in rural areas), and age of vehicle by vehicle design variables and by sex of driver and age of driver, etc.

J7. Kent, Perry M. Guide for Truck Weight Study Manual, Washington: Federal Highway Administration, 1971.

Chapter IV describes a recommended method for obtaining state commodity movement by mail. based on pilot tests in three states in which samples of registered trucks were sent a mail questionnaire asking about travel on a particular future day; the average initial response rate was $24.5 \%$ with no reminder, $26.7 \%$ with a phone reminder on the travel day or the next day, and $27.0 \%$ with a mail reminder posted to arrive on the travel day or the next day; with follow-up questionnaires sent one and two weeks later to non-respondents the average response rate was brought up to $78.1 \%$. The questionnaire asks about vehicle type, load, and location at 2 AM on the travel date and at up to 10 destinations on the travel day including mileage and purpose of each trip plus a 24-hour mileage estimate.

J8. Morison, I.W. "Canberra - A Review of Recent Traffic Studies", Proceedings of the 1962 Conference of the Australian Road Research Board. Vol. T, Part 1, pp. 376-387.

Describes an origin-destination survey in Canberra using a post card method to obtain origin, destination, time, purpose, and means of all trips on one week day; cards were mailed to registered vehicle owners and handed to drivers of government vehicles and to bus passengers - obtained almost a 50\% response rate with the assistance of press and radio publicity.

39. Planek, Thomas W. and Richard C. Fowler. "Traffic Accident Problems and Exposure Characteristics of the Aging Driver", Journal of Gerontology 26(2):224-230 (1971).

Discussion of a mail questionnaire sent to 5000 Illinois drivers over 55, and 1000 California drivers over 55; with 1 follow-up mailing the 111 inois response rate was $48.1 \%$ and the California response rate was $43.8 \%$; also included in the analysis were 789 questionnaires returned out of 1500 distributed by the American Association of Retired Persons. Data elements included estimated annual mileage, frequency of driving, frequency of rush hour driving, percentage of after dark driving, decline in winter driving, percentages of driving on four types of roads, own perceived driving faults, and own perceived operational driving problems. 
K. COMPARISONS OF VARIOUS EXPOSURE DATA COLLECTION METHODS

K1. Carroll, Philip S. et al. Acquisition of Information on Exposure and Non-Fatal Crashes, Ann Arbor: HSRI, 1971.

Section 5 of Volume I briefly mentions a number of special surveys conducted among Washtenaw County license renewal applicants (see H2). Roughly comparable response rates were obtained for office interviews and office questionnaires (88\%$92 \%)$, while an office interview plus 2 mail-back odometer postcards had a $54 \%$ response rate, an office interview with a mailback trip $\log$ had a $59 \%$ response rate, an office selfadministered questionnaire with a mailback trip log had a $50 \%$ response rate, and a telephone interview with a sample obtained at the office had a $58 \%$ response rate (without repeat calls).

K2. DiRenzo, John F. and Robert A. Ferlis. Guidelines for Designing Travel Surveys for Statewide Transportation Planning, Washington: Peat, Marwick, Mitchell, and Co., May 1976.

Includes an overview of survey design concepts and issues; a discussion of sample design and estimated levels of precision in household surveys; a discussion of the advantages, disadvantages, and recommended procedures for in-person, mail, and telephone methods; advice on adjustments for nonresponse; and discussion of sampling procedures and precision levels for roadside surveys with various purposes.

Appendices include some comparative tables of data from various travel surveys and an illustration of procedures for calculating the design effect and variance in cluster samples.

K3. DiRenzo, John F. Travel Survey Procedures for Statewide Transportation Planning, Washington: Peat, Marwick, Mitchell, and Co., April 1976.

A review of various procedures for conducting household travel surveys, roadside surveys, and model surveys including a few studies which compare the effectiveness of alternative methods. Among the household data cited was a $92 \%$ response rate in a Connecticut face-to-face interview survey, a $40 \%$ response rate in a Kentucky mail survey (plus $5 \%$ by telephone or face-to-face interview), a $63 \%$ response rate in an upstate New York telephone interview, and a $90 \%$ response rate in a Delaware telephone interview. Three community studies comparing the in-person and telephone interview methods (Kalamazoo, Marysville-Yuba City, and Spokane) concluded that either method was satisfactory but that the telephone might lead to underreporting of trips. A New Haven study by the Census Bureau compared a mail questionnaire with an in- 
person interview; the respondents to the initial mailing had a very high average number of trips, but this average declined among respondents to the second mailing and to later telephone and in-person follow-up interviews.

Roadside follow-up techniques reviewed include a Northeast Corridor study comparing an interview plus a mailback survey ( $36 \%$ mailback response) to a stop plus a mailback survey (only $18 \%$ response), and a San Francisco-Sacramerto Corridor Study in which license plates were recorded and a mail-back survey was distributed by mail to the vehicle owners (74\% response).

Appendices give fuller details about the above-mentioned and other studies including a number of license plate matching mail surveys.

K4. Federal Highway Administration. Urban Origin-Clestination Surveys: Dwelling Unit Survey, Truck and Taxi Surveys, External Survey, Washington, reprinted July $1975,309 \mathrm{pp}$.

The most recent update of a procedural guide for conducting a comprehensive origin-destination survey, first published by the Bureau of Public Roads in 1944 and last revised in 1954. The guide includes detailed advice about sampling and data collection methods for dwelling unit trips on a travel day, including in-person home interview, telephone interview, and self-administered questionnaire methods; about roadside data collection methods for trips crossing the external cordon line around the study area, including interview and postal survey methods and an appendix on roadside interviewing at high volume stations; about procedures for special surveys of trips on specified travel days of trucks and taxi samples; about data processing procedures, quality control methods, and accuracy checks against other data sources; and about special purpose surveys such as mass transit surveys, intercity bus surveys, airport surveys, parking surveys, etc. A glossary and a lengthy appendix provide useful examples of ideas discussed in the text.

K5. Kobas, G.V. and C.G. Drury. "The Bicyclists' Exposure to Risk", in Proceedings of the 6 th Congress of the International Ergonomics Association, College Park, Md., July 11-16, 1976, pp. 484-487.

A brief report of two surveys of bicyclists in the Buffalo area; one was a mail survey in which bicyclists were asked to provide a detailed description of the route of their last bicycle trip plus other pertinent information about themselves and their bicycle; the other was a roadside survey in which bicyclists were stopped and interviewed about their current journey etc. 
K6. Shoul, Jean. Factors Which Constrain the Variability of a Group's Mileage and Other Exposure Variables, Salford, England: Road Safety Research Unit, University of Salford, 1976.

A partial report of an elaborate panel survey of the driving behavior of three groups of sixth form high school students: those with a pre-driving course including classroom instruction and some off-road car instruction, those with a driver education course which also included considerable on-road instruction, and those with no high school driver training. Three different panels were selected from the 1969-70, 1970-71, and 1971-72 school years, each to be followed up at 6-9 month intervals till 1974; thus there were 8 contacts with the first pane1, 6 contacts with the second panel, and 5 contacts with the third panel. The initial data collection was by group-administered questionnaire in the schools, while the subsequent data collections alternately used home in-person interviews and postal questionnaires as the primary method; since many of the sample members were University students the data collections were scheduled for holiday periods; high response rates were obtained with final analysis driver sample of 569 male and 349 females. Data elements collected included estimated total mileage ever, last 7 days mileage, average weekly mileage, rough proportions of nighttime and motorway driving, most frequent driving purpose, general seat belt use, general passenger types, ownership and type of normally driven vehicle, accident history, and traffic offense history.

K7. Traffic and Operations Dept., Highway Research Board. "New Concepts in 0-D Studies", 1967 Origin and Destination Committee Meeting, Washington.

Discussion of use of drop-off and pick-up self-administered questionnaires in Ohio and of telephone interviewing methods in dwelling unit trip surveys.

K8. Urban Transportation Systems Associates. "Evaluation of Alternative Data Collection Techniques", Rhode Island Statewide Origin-Destination Study: Task 4 Report, Providence: State of Rhode Island, 1970.

Includes a comparison of telephone and in-person home interview methods in Rhode Island trip surveys. 


\section{COMPARISONS OF VARIOUS EXPOSURE MEASUREMENTS METHODS}

L1. Carroll, Philip S. et al. Acquisition of Information on Exposure and on Non-Fatal Crashes, Ann Arbor: HSRI, 1971

Section 5 of Volume I reports a small study of the accuracy of 7 -day mileage estimates; in the 1969 preliminary exposure survey of Washtenaw County 1 icense renewal applicants (see H2) 448 interviewees were asked to return two odometer-reading postcards at about one-week intervals, and 54\% cooperated by returning both cards; the comparison of the odometer mileage and the respondents 7-day estimate of personal driving is confounded by the different time periods, by the fact that someone else might drive the same vehicle, and conversely by the fact that the respondent might drive some other vehicles. For the 242 cases the mean 7-day respondent estimate was 297 with a standard deviation of 456 , while the mean 7-day vehicle odometer mileage was a smaller 276 with a standard deviation of 261; the much larger standard deviation of the estimated mileage is indicative of the unreliability of some estimates, but unfortunately the standard deviation of individual differences is not given.

Appendix $G$ of Volume IV indicates that in the national pilot survey the mean 30-day mileage estimate was 1013 with a standard error of 1400; $50 \%$ of the respondents gave answers to the nearest 100 and $22 \%$ gave answers to the nearest 1000 ; if one assumed an average of 50 miles rounding error that would still seem to be only a small part of total error.

L2. House, Elizabeth G. and Patricia F. Waller. Accuracy of Drivers' Estimates of Vehicle Miles Driven, Chapel Hill: University of North Carolina Highway Safety Research Center, 1971.

Report of a study to test the accuracy of mileage estimates by unobtrusively observing the odometers of University-registered cars in University parking lots and sending mail questionnaires to the owners; 2276 odometers were successfully read in the fall of 1969,2245 questionnaires were sent to owners in the spring of 1970, and 806 of these odometers were read again in the spring of $1970 ; 5.7 \%$ of the questionnaires were returned unopened, of the remainder $80 \%$ were completed after one follow-up mailing three weeks later; each respondent was asked to estimate the monthly and annual mileages on the car he or she usually drove plus percentages the car was driven by someone else, was driven during the three summer months, was driven in town, and was driven for business purposes; a total of 505 cases had both odometer readings and a driver estimate for that car, and the 
$r$ correlation between actual and estimated monthly mileage was 0.65 ; there were more over-estimates than under-estimates of monthly mileages compared to the actual mean of 903 miles (with a standard devfation of 427 miles); half of the monthly estimates differed by more than 200 miles, and $10 \%$ differed by more than 600 miles; a simple 2-factor formula was developed which made an $18 \%$ improvement in the whole-sample prediction of actual monthly mileage from estimated monthly mileage.

L3. Negri, D. Barry, Vehicle Mileage Exposure Study: Final Report, Report DOT-HS-800 961 from Contract DOT-HS-245-2-476, Sept. 1973.

Used over one million pairs of 1970-72 odometer readings from N.Y. inspection receipts to obtain annual vehicle mileages; then compared these actual mileages with two methods of extrapolating annual mileages from a single odometer reading. The first assumed uniform daily mileage from April l of the vehicle model year to the date of the odometer reading. The second method involved comparing the average odoneter readings for each make/model year group over 2 years. In comparisons of the group averages by the two methods with the actual group averages the second method always gave too low results, while the first method was more accurate except for the two newest models where the extrapoiations tended to be too high and for some of the older models where they tended to be somewhat low (surprisingly).

L4. Research Triangle Institute Environmental Analys is Department. Improved Exposure Measures: Interim Report, December 1972.

Chapter 3 contains a comparison of two annual mileage estimates obtained from the 1969-70 National Personal Transportation Study (one based on the annual estimate and the other based on conversion of the 1 day trip mileage) and of three annual mileages from HSRI's 1970 national study of driver license renewal applicants (one based on conversion of the 30 day estimate, one based on conversion of the 7 day estimate for all drivers, and one based on conversion of the 7 day estimate for drivers of only one car). Within the NPTS the annual estimates were considerabiy larger than the 1-day conversions, but both NPTS figures were substantially less than the three HSRI figures for each of six age-sex classes; within the HSRI study the 7-day conversions were quite a bit higher than the 30-day conversions for all six groups. Of course no independent validation data were available for either study (although its' of interest that FHWA annual mileage estimates are in between the NPTS annual estimate and the HSRI 30-day conversion). 
L5. White, S.B. "On the Use of Annual Vehicle Miles of Travel Estimates from Vehicle Owners", Accident Analys is and Prevention 8(4):257-261 (Dec. 1976). (Also reported briefly in Section 4 and Appendix $D$ of RTI's Improved Exposure Measurements: Final Report, 1976, but with somewhat different figures).

The Research Triangle Institute sent mail questionnaires to a sample of 911 North Carolina motor vehicle owners whose vehicles had been inspected in Oct. 1974. There was a $63 \%$ response rate with one follow-up mailing after 3 weeks, only 433 of these cases also had a satisfactory pair of odometer readings from the inspection receipts (approximately 12 months apart). The annual mileages obtained from the odometer readings were compared with owner estimates of 12-month vehicle mileages, and there was an $r$ correlation of 0.67 . The mean was only 423 greater for the estimated vehicle VMT than for the actual vehicle VMT, but the standard deviation of the individual differences was 5363 miles. Thus individual estimates exhibited a great degree of unreliability, but the overall estimated mean seemed fairly reliable. In particular owners tended to overestimate VMT for low mileage and older vehicles and to underestimate VMT for high mileage vehicles, which could have important effects on analyses using mean estimates in certain subgroups such as older vehicles. 